\title{
THE BEHAVIOR OF EXTERNAL DEBT IN ASIAN COUNTRIES: EVIDENCE BASED ON PANEL UNIT ROOT TESTS
}

\author{
Evan Lau ${ }^{1}$, Ahmad Zubaidi Baharumshah ${ }^{2}$, Siew-Voon Soon ${ }^{3}$ \\ ${ }^{1}$ Department of Economics, Faculty of Economics and Business, Universiti Malaysia Sarawak \\ (UNIMAS), 94300 Kota Samarahan, Sarawak, Malaysia \\ ${ }^{2,3}$ Department of Economics, Faculty of Economics and Management, Universiti Putra \\ Malaysia, 43400 UPM Serdang, Selangor Darul Ehsan, Malaysia \\ E-mails: ${ }^{1}$ lphevan@feb.unimas.my; ${ }^{2}$ baharumshah@yahoo.com (corresponding author); \\ ${ }^{3}$ sv_soon2001@yahoo.com
}

Received 21 October 2011; accepted 06 August 2012

\begin{abstract}
This article investigates the mean-reverting behavior of the external debt ratio based on a clustered of 19 Asian countries from 1981 to 2010. For this purpose, we use a government's intertemporal budget constraint (GIBC) model popularized by Hamilton and Flavin (1986). Our conclusions were drawn from panel data based tests, including the newly developed test that accounts for both cross-sectional dependency and structural breaks. Two major findings are noteworthy; first majority debt ratios in the Asian countries are affected by structural breaks. Second, we find unit root tests that do not accommodate breaks are less likely to detect mean reversion in the debt ratios. In all, our results indicate debt sustainability is a general characteristic of all the Asian countries.
\end{abstract}

Keywords: external debt, mean reversion, Government Intertemporal Budget Constraint (GIBC), breaks, Asian.

Reference to this paper should be made as follows: Lau, E.; Baharumshah, A. Z.; Soon, S.-V . 2013. The behavior of external debt in Asian countries: evidence based on panel unit root tests, Journal of Business Economics and Management 14(Supplement 1): S377-S394.

JEL Classification: F34, H63, C22, C51.

\section{Introduction}

The wave of currency crises and international debt in 1990s brings about a question of how sustainable are the foreign aids for a recipient country in order to protract its economic growth ${ }^{1}$. The relevance of the sustainability of external debts has been highlighted in recent years. The external debts are said to be sustainable when a country can meet its current and future external debt service obligations in full (Thugge, Boote 1997). In other words, sustainability would require that indebtedness be kept in line with

\footnotetext{
${ }^{1}$ Reinhart and Rogoff (2009) provide an excellent and comprehensive chronicle of the financial 'folly' through the eight centuries that also covers the debt crises in the developing countries. The episodes of sovereign external debt crises were narrated in detail.
} 
the capacity of the borrower to repay. In the case where a country faces a very high level of debt ratios, debt servicing would not just constraint the economic performance, but can be nearly impossible to achieve ${ }^{2}$. Economies that let their debt grow over a longer time period face the danger that it may exceed the debt-targeting threshold (Fincke, Greiner 2011). This is especially true for developing countries in making wide-ranging decisions about public spending, taxation and borrowing (Cassimon et al. 2008). It is important for a country to determine how much they can borrow without jeopardizing its long-term growth prospects, which would be an important part of the national economic agenda. The scenarios may have worsened with the recent global financial meltdown where numerous fiscal stimulus packages have been introduced and these bring additional pressure to the external debt position, especially in the developing countries. Many countries around the world, including those under review, have accumulated a large debt in the aftermath of the global financial crisis (GFC) (Baldacci et al. 2010). The challenge ahead for these governments is not only to regain fiscal stability, but with an unprecedented simultaneous increase in debt levels worldwide, it makes this effort particularly challenging, especially for developing nations that pursue an export-led growth strategy. In fact, recent data has shown the scenario has also worsened in the advanced economies.

The literature on external vulnerability and insolvency of a country are vast and took place after the foreign debt crisis in the early 1980's. Some of the earlier contributions were from McFadden et al. (1985) and Berg and Sachs (1988). Most of these studies attempt to analyze the determinants of debt servicing difficulties in the first wave of debt crisis. After the 1997 Asian financial crisis, researchers have been more interested on the sustainability of external debt and insolvency issue (see Chaudhary, Anwar 2001; Önel, Utkulu 2006, to name a few). For example, external debt and current account deficits were found to be unsustainable in Brazil, while some countries (e.g. Ukraine or Pakistan) have been on a sustainable path. The major concerns are about the large lumpy debt services and the limited access to the global financial markets, especially during financial trauma. Kraay and Nehru (2006), on the other hand, argue that risk of insolvency depends significantly on three major factors; (i) debt burdens, (ii) policies and institutions and (iii) shocks. For the case of Turkey, Önel and Utkulu (2006) took up this issue and found evidence of 'weakly' sustainable external debt with a caution of rising stock of debt. It is worth noting that a recent paper by Muhanji and Ojah (2011) found that both world commodity price and interest rate shocks have a significant impact on the external debt accumulation in majority of the African countries under review.

${ }^{2}$ Kim et al. (2009) defined sustainability of external debts as a country's ability to pay its external obligation without resorting to substantial readjustments of exchange rates or default in paying debts. 
This paper examines the behavior of total external debts in 19 selected Asian countries using an array of unit root and stationarity tests ${ }^{3}$. If the results reveal that the external debt follows a nonstationary process, then it implies that shocks to external debt are permanent; resulting in insolvency of its external debt repayment. On the other hand, if the results indicate the variable is stationary then the countries are said to be solvent in terms of its external debt having a temporary effect of shocks. From a policy point of view, it is crucial to determine whether it will be necessary to curtail the imbalances in order to avoid "hard landing" or economic crisis if the necessary adjustments are delayed. We depart from the past literature by considering a new panel procedure based on Carrion-i-Silvestre et al. (2005, CDL) to address the issue of cross dependency and multiple structural breaks ${ }^{4}$.

Many of the Asian countries under review pursue export-led growth supported by pegging their currency to the US dollar. In the past three decades, cross-border lending in Asian has increased sharply from $\$ 161$ billion in 1985 , to $\$ 204$ billion in 1990 , to a peak of \$534 billion in 1997. The 1997 Asian financial crisis started in Thailand and Indonesia before spreading slowly to the northeast side of Asia, victimizing countries like South Korea and the Philippines. The International Monetary Fund (IMF) responded immediately to this crisis by providing financial assistance to the three most severely affected countries - Indonesia, Thailand and South Korea - with an economic stabilization and reformation program. However, the trend in the debt-to-gross domestic product (GDP) ratios in most of the Asian countries showed a noticeable improvement in the post-crisis period. In the Asia and Pacific region, the ratio had fallen to $26 \%$ from $41 \%$ in 1998. Many countries in the region have improved their external positions due to debt restructuring and macroeconomic adjustment programs. It should be noted that the macroeconomic adjustments pursed in the Asian crisis-affected countries resulted in reduced demand for external financing. The development of domestic bond markets in some of the countries under review (e.g., India, Indonesia, Malaysia and Turkey) has also contributed to the debt reduction in the last decade.

With the motivation and objective in place, this paper is set out as follows. The next section describes the theoretical model. This is followed by the testing procedures adopted in the study. We then present the empirical results and discuss the findings. The final section summarizes major conclusions of the empirical research.

\footnotetext{
${ }^{3}$ The countries involved in this research are Bangladesh, Bhutan, China, India, Indonesia, Iran, Jordan, Lao People's Democratic Republic (Lao PDR), Malaysia, Maldives, Nepal, Oman, Pakistan, the Philippines, Sri Lanka, Syria, Thailand, Turkey and Vietnam. Using the data set from 118 developing countries including selected countries here, Johansson (2010) finds in general, the absence of the growth effect of debt relief especially for the Highly Indebted Poor Countries (HIPC). Accordingly, Nepal is in the group of HIPC while countries like Bangladesh, India, Lao PDR, Pakistan and Vietnam were categorized as low-income countries. The remaining countries were in the middle-income category.

${ }^{4}$ We note that several studies also have applied nonlinear unit root tests to address the sustainability issue (see Kim et al. 2009; Christopoulos, León-Ledesma 2010).
} 


\section{Theoretical framework}

The standard procedure in most empirical contributions on long-run debt sustainability consists of testing the government's intertemporal budget constraint (GIBC). A partial list of past studies that apply the model would include Hamilton and Flavin (1986), Quintos (1995), Trehan and Walsh (1988, 1991), Bajo-Rubio et al. (2009), and Takeuchi (2010). The model starts with the budget constraint faced by the government at period $t$ written as

$$
b_{t}=\left(1+r_{t}\right) b_{t-1}+d_{t},
$$

where $b_{t}$ is the government debt, $r_{t}$ is the (one period) real ex post rate of interest adjusted for real output growth and $d_{t}$ is the external debt. Both $b_{t}$ and $d_{t}$ are scaled by GDP.

The budget constraint to Equation (1) pertains only to the period $t$. Subsequently, there is a similar constraint as Equation (1) for periods of $t+1, t+2, t+3, \ldots \ldots, t+n$ and by recursive solving the equation via forward substitutions leads to:

$$
b_{t}=-E_{t} \sum_{i=1}^{n} \delta_{t, i} d_{t+i}+E_{t} \delta_{t, n} b_{t+n}
$$

where $\delta_{t, n}=\Pi_{s=1}^{n}\left(1+r_{t+s}\right)^{-1}$ is the $n$ time-varying real discount factor and $E_{t}$ denotes conditional expectations. $\delta_{t, n}$ can also be expressed as $\delta_{t, n}=q_{t+n} / q_{t}$ where $q_{t}=\Pi_{i}^{t}\left(1+r_{i}\right)^{-1}$ is the sequence of the discount factors from period $t$ back to the period 1 with $q_{0}=0$. Defining $B_{t}=q_{t} b_{t}$ and $D_{t}=q_{t} d_{t}$ as the discounted debt to GDP ratio and external debt to GDP ratio, respectively, Equation (2) can be written as $q_{t} b_{t}=-E_{t} \sum_{i=1}^{n} q_{t+i} d_{t+i}+E_{t} q_{t+n} b_{t+n}$ or more compactly expressed as

$$
B_{t}=-E_{t} \sum_{i=1}^{n} D_{t+i}+\lim _{n \rightarrow \infty} E_{t} b_{t+n} .
$$

Equation (3) shows that the current value of government debt $B_{t}$ is equal to the expected present value of all future external debt $\sum_{i=1}^{n}\left[D_{t+i}\right]$, plus a limiting term that represents the asymptotic expected present value of the government's debt.

A necessary and sufficient condition for sustainability is that the expectation of the discounted debt to GDP ratio should converge to zero as the planning horizon recedes (Makrydakis et al. 1999; Uctum, Wickens 2000). In notation, it implies that the last element in Equation (3) $\left[\lim _{n \rightarrow \infty} E_{t} b_{t+n}\right]$, where the limit taken as $n \rightarrow \infty$ shows the infinite planning horizon. When the limit term is set to zero $\left[\lim _{n \rightarrow \infty} E_{t} b_{t+n}=0\right]$, it means that we have ruled out a Ponzi scheme in the long-run. In other words, the government is not "bubble" financing its expenditure by issuing new debts to finance the external debt. Therefore, external debt will be sustained if the limiting term equals to zero. A non-Ponzi game restriction is typically regarded as synonymous with sustainability, which implies that the transversality condition has to hold. If this condition is satisfied, the GIBC can be expressed as

$$
B_{t}=-E_{t} \sum_{i=1}^{n} D_{t+i}
$$


Equation (4) states that for the external debt to be sustainable in the long-run, the authorities should run a sequence of discounted future non-interest external debt capable of offsetting the current outstanding debt. A formal assessment on the sustainability condition is to test whether the government external debt follows an $I(0)$ process. Hence, the sustainable external debt typically assumes the stationary property of the debt variable or follows a mean-reverting process. The sustainable notion of debt position can be objectively verified using the statistical/econometric concepts where an indicator such as external debt relative to GDP is readily made available in a country ${ }^{5}$.

\section{Data and methodology}

\subsection{Data description}

Annual data of total external debt stock and GDP (in US dollar) spanning from 1981 to 2010 were utilized in this study. For some countries, quarterly frequency data are long-standing and up to date. For others, the data is more recent or is unavailable ${ }^{6}$. All datasets for the 19 sample countries are extracted from the World Development Indicators and IMF. The annual frequency data were converted into a ratio of external debt to GDP before the empirical analysis is carried out.

\subsection{Univariate unit root and stationarity tests}

In this study, we first apply the univariate testing procedures of Said and Dickey (1984, Augmented Dickey-Fuller, ADF), KPSS (1992) and Elliott et al. (1996, DFGLS) to examine the time series property of GIBC. Although the ADF and DFGLS tests share the same null hypothesis of a unit root, the DFGLS procedure relies on locally demeaning and/or detrending a series prior to the implementation of the usual auxiliary ADF regression. On the contrary, the KPSS test utilizes the null hypothesis of a non-unit root for both the level and trend form of the testing procedures.

\subsection{Panel unit root tests}

In addition to the univariate testing, the current article employs two panel-based unit root tests (Levin et al. 2002, LLC and Im et al. 2003, IPS) for same set of data series. Several authors have documented that even for long-run data the available time series unit root and stationarity tests suffer from severe size distortion and low power in most applications. Consequently, the empirical literature has shifted to panel methods that are

\footnotetext{
${ }^{5}$ Our finding appears to be consistent with much-cited stationary condition for sustainability (e.g., Trehan, Walsh, 1988; Ahmed, Rogers, 1995). However, Bohn (2007) has proven that stationary is sufficient but not necessary for sustainability in debt. We thank an anonymous referee who pointed out this concern.

${ }^{6}$ Low frequency data does not present a major drawback. Indeed, recent studies have shown that monthly or quarterly macroeconomic variables tend to be more persistent than the annual series. Accordingly, the Kwiatkowski et al. (1992, KPSS) test is shown to over-reject the stationary null when the series is persistent. Since the CDL (2005) and Hadri (2000) tests are extensions of the KPSS tests, this motivates us to use annual rather than quarterly data.
} 
known to exhibit better performance. Whether such a claim is true or not is, however, unclear (Hlouskova, Wagner 2006). We refrain from discussing the procedures in any detail here given that these tests are widely used in the literature.

\subsection{Series-specific panel unit root test - Breuer et al. (2002, SURADF)}

A common feature of the panel unit root test is that they maintain the null hypothesis of a unit root in all panel members; the sole exception is the Hadri (2000) test. Therefore, their (non-) rejection suggests that at least one panel member is stationary, with no information on the number of series or which ones are stationary. Apart from that, the series-specific panel unit root tests - seemingly unrelated regressions augmented Dickey-Fuller (SURADF) — initiated by Breuer et al. (2002) were deployed to overcome the "all or nothing nature" of the earlier panel unit root tests. The SURADF test is based on the system of ADF equations which can be represented as:

$$
\begin{aligned}
& \Delta y_{1, t}=\alpha_{1}+\beta_{1} y_{1, t-1}+\sum_{j=1} \varphi_{j} \Delta y_{1, t-j}+u_{1, t}, \\
& \Delta y_{2, t}=\alpha_{2}+\beta_{2} y_{2, t-1}+\sum_{j=1} \varphi_{j} \Delta y_{2, t-j}+u_{2, t}, \\
& \vdots \\
& \Delta y_{N, t}=\alpha_{N}+\beta_{N} y_{N, t-1}+\sum_{j=1} \varphi_{j} \Delta y_{N, t-j}+u_{N, t},
\end{aligned}
$$

where $\beta_{j}=\left(\rho_{j}-1\right), \rho_{j}$ is the autoregressive coefficient for the series $j$ and $t=1, \ldots, T$. This system is estimated by the SUR procedure with null and the alternative hypotheses are tested individually as:

$$
\begin{array}{ll}
H_{0}^{1}: \beta_{1}=0 ; & H_{A}^{1}: \beta_{1}<0, \\
H_{0}^{2}: \beta_{2}=0 ; & H_{A}^{2}: \beta_{2}<0, \\
\vdots & \\
H_{0}^{N}: \beta_{N}=0 ; & H_{A}^{N}: \beta_{N}<0,
\end{array}
$$

with the test statistics being computed from SUR estimates of system (6) while the critical values are generated by Monte Carlo simulations.

This procedure poses several advantages. First, it exploits the information from the error covariances and accounts for the autoregressive process while producing efficient estimators over the conventional single-equation methods. Second, the estimation also allows for a heterogeneous fixed effect, heterogeneous trend effects and heterogeneity in lag structure across the panel members. Third, unlike the predecessors, SURADF test allows us to identify how many and which member(s) of the panel contain a unit root. As this test has nonstandard distributions, the critical values of the SURADF test must be obtained through simulations. With respect to the Monte Carlo simulations, the intercepts, the coefficients on the lagged values for each series were set equal to zero. The lagged differences and the covariance matrix were obtained from the SUR estimation on the actual 19 selected Asian country data.

The SURADF test statistic for each of the 19 series was computed as the $t$-statistic calculated individually for the coefficient on the lagged level. Since the method of estimation takes into account error correlation, which will be different for different series, 
the critical values for SURADF will be different for each series. In order to obtain the critical values, the experiments were replicated 10,000 times and the critical values of 1, 5 and $10 \%$ were tailored to each of the 19 panel member countries. Lau and Baharumshah (2009) applied the panel SURADF method to determine the mean-reverting pattern of the fiscal imbalances on 10 Asian countries. They showed that the standard panel unit root tests tend to favor mean reversion while the series-specific unit root test rejects the null of nonstationarity in only four out of the 10 countries. Potential structural breaks in the economic process were not considered in their analysis. A structural break within the panel framework is discussed in the next section.

\subsection{Panel data stationarity test with structural breaks}

A panel stationarity test developed by the CDL (2005) is a generalization for the case of multiple structural breaks of the panel stationarity test of Hadri (2000). It is an application of the Lagrange Multiplier (LM) test, which specifies the null hypothesis of stationarity for cross-sections. According to CDL (2005), the procedure is general enough to allow the following characteristics: (i) structural breaks can have heterogeneous effects on each individual time series; (ii) these breaks can be located at different dates and (iii) individuals can have a different number of structural breaks. Let $y_{i, t}$ be the stochastic process which characterized by the following data generation process:

$$
y_{i, t}=\alpha_{i}+\beta_{i} t+\sum_{k=1}^{m i} \gamma_{i, k} D U_{i, k, t}+\sum_{k=1}^{m i} \vartheta_{i, k} D T_{i, k, t}+\varepsilon_{i, t},
$$

where $y_{i, t}$ is external debt to the GDP ratio for number of panel members, $i=1 \ldots N$, at time, $t=1 \ldots T$, with disturbance term, $\varepsilon_{i, t}$. The $\alpha_{i}$ is country-specific time-invariant compensating differentials, which allows for conditional convergence. The $\beta_{i} t$ is the country-specific linear time trends. The dummy variables for the changes in the level is given by $D U_{i, k, t}$ which $D U_{i, k, t}=1$ for $t>T_{b, k}^{i}$ and zero elsewhere, with $T_{b, k}^{i}$ denoting the $k$ th break location for the $i$ th individual for $k=1 \ldots m_{i}, m_{i} \geq 1$. The variable $D T_{i, k, t}=t-T_{b, k}^{i}$ for $t>T_{b, k}^{i}$ and zero otherwise. The Equation (7) includes individual effects, individual structural break effects $\left(\beta_{i} \neq 0\right)$, and temporal structural break effects $\left(\vartheta_{i, k} \neq 0\right)$ for each individual. The different unknown numbers of breaks may have different effects (measured by $\gamma_{i, k}$ and $\vartheta_{i, k}$ ) on each individual time series. The general expression for the test statistic is:

$$
\operatorname{LM}(\lambda)=N^{-1} \sum_{i=1}^{N}\left(\omega_{i}^{-2} T^{-2} \sum_{t=1}^{T} S_{i, t}^{2}\right)
$$

with $\eta_{i}\left(\lambda_{i}\right)=\hat{\omega}_{i}^{-2} T^{-2} \sum_{t=1}^{T} \hat{S}_{i, t}^{2}$ is the univariate KPSS test for $i, \hat{\omega}_{i}^{2}$ stands for the consistent estimate of the long-run variance of the $\varepsilon_{i, t}, \hat{\omega}_{i}^{2}=\lim _{T \rightarrow \infty} T^{-1} E\left(S_{i, T}^{2}\right), i=1, \ldots, N$ and $\hat{S}_{i, t}^{2}=\sum_{j=1}^{t} \hat{\varepsilon}_{i, j}$ is the partial sum process that is obtained using the estimated ordinary least squared (LS) residuals of Equation (7). This allows the disturbance to be heteroscedastic across the cross-sectional dimension. The LM test is dependent on the location of the breaks $(\lambda)$, which is unknown. It is defined as the vector $\lambda_{i}=\left(\lambda_{i, 1}, \ldots, \lambda_{i, m_{i}}\right)^{\prime}=\left(T_{b, 1}^{i} / T, \ldots, T_{b, m_{i}}^{i} / T\right)^{\prime}$ which indicates the relative positions of the dates of breaks on the entire time period. Under the null hypothesis of a stationarity 
panel with multiple breaks, the test statistic $Z(\lambda)$ is shown to follow the standard Gaussian law:

$$
Z(\lambda)=\left[\frac{\sqrt{N}(L M(\lambda)-\bar{\xi})}{\bar{\zeta}}\right] \rightarrow N(0,1)
$$

where $\bar{\xi}=N^{-1} \sum_{i=1}^{N} \xi_{i}$ and $\bar{\zeta}^{2}=N^{-1} \sum_{i=1}^{N} \varsigma_{i}^{2}$, with $\xi_{i}$ and $\varsigma_{i}^{2}$ are computed as average of individual means and variance of univariate KPSS tests $\left[\eta_{i}\left(\lambda_{i}\right)\right]$. Rejection of the null hypothesis implies divergence for at least one country, while nonrejection of the null implies stochastic convergence in all countries. Homogeneity $\left(L M(\lambda)=N^{-1} \sum_{i=1}^{N}\left(\omega^{-2} T^{-2} \sum_{t=1}^{T} S_{i, t}^{2}\right)\right.$ with $\left.\hat{\omega}^{2}=N^{-1} \sum_{i=1}^{N} \hat{\omega}_{i}^{2}\right)$ and heterogeneity as Eqaution (8) in the estimation of the long-run variance across individuals imposed for robustness.

\section{Empirical results and discussion}

\subsection{Univariate unit root and stationarity tests}

We begin the discussions with the analysis on the standard univariate unit root tests of the series. The results are reported in Table 1 and two points are worth noting here. First, both the ADF and DFGLS tests suggest that the unit root null cannot be rejected at the standard significance levels. There are a few exceptions (at most five) where the null of unit root for either constant or constant plus trend models. In all, the tests support the hypothesis that each of the series is stationary only after taking the first difference. Second, the KPSS tests do not conform to the results of the other unit root tests. The stationarity null cannot be rejected in 11 cases for the constant model and one additional in the constant plus a trend model at the indicated significance levels.

Therefore, it appears that the results from these univariate tests are sensitive to the choice of a particular testing procedure. Mixed results were obtained for the external debt ratio series and no confirmation can be established with regard to the stochastic process for each of the series under investigation. In other words, for the series that appear to be nonstationary in seven countries (China, Nepal, Oman, Pakistan and Sri Lanka, just to name five); it is premature at this point to conclude that the external debts are unsustainable paths. As usually noted, these results cannot be conclusive due to the well known power problem of their test statistics leading to over-acceptance of the null.

\subsection{Panel unit root tests}

Taking note of the low power of univariate data based tests in small samples, we reexamined the stationarity of the set of series using an array of panel procedures. Results for the first generation panel unit root tests may be summarized as follows. It is evident from the application of both the IPS (2003) and the LLC (2002) statistics that the unit null hypothesis of joint nonstationarity were rejected at the usual significance levels. For example, the findings from the IPS tests with $[W=-1.328$; $p$-value $=0.092]$ or without trend variable $[W=-1.378 ; p$-value $=0.084]$ in the regression. Similarly, the LLC statistics based on the model with intercept only $[N=-1.338 ; p=0.091]$ and intercept 
Table 1. Unit root tests

\begin{tabular}{|c|c|c|c|c|c|c|c|c|c|c|c|}
\hline & \multicolumn{3}{|c|}{$\mathrm{ADF}$} & \multicolumn{4}{|c|}{ KPSS } & \multicolumn{4}{|c|}{ DFGLS } \\
\hline & $\theta$ & & $\tau$ & $\theta$ & & $\tau$ & & $\theta$ & & $\tau$ & \\
\hline \multicolumn{12}{|c|}{ Level external debt to GDP } \\
\hline Bangladesh & -1.833 & {$[0]$} & $-2.491 \quad[0]$ & 0.203 & (4) & $0.169^{\mathrm{b}}$ & (4) & -1.241 & {$[0]$} & -1.682 & [0] \\
\hline Bhutan & -1.381 & {$[0]$} & $-2.205 \quad[0]$ & $0.640^{\mathrm{b}}$ & (4) & 0.079 & (2) & -0.875 & {$[0]$} & -2.404 & [0] \\
\hline China & -2.066 & {$[0]$} & $-1.360 \quad[0]$ & $0.434^{\mathrm{c}}$ & (2) & $0.175^{\mathrm{b}}$ & (4) & -1.240 & {$[0]$} & -1.096 & [0] \\
\hline India & -1.698 & {$[1]$} & $-2.261 \quad[2]$ & 0.163 & $(4)$ & $0.156^{\mathrm{b}}$ & (4) & -1.437 & [1] & -1.583 & [1] \\
\hline Indonesia & -2.282 & {$[0]$} & $-2.151 \quad[0]$ & 0.157 & $(4)$ & $0.153^{b}$ & (4) & $-2.054^{b}$ & {$[0]$} & -2.196 & [0] \\
\hline Iran & $-2.937^{\mathrm{c}}$ & {$[0]$} & $-2.853[0]$ & 0.133 & (4) & $0.131^{\mathrm{c}}$ & (4) & $-2.848^{\mathrm{a}}$ & {$[0]$} & $-2.941^{\mathrm{c}}$ & [0] \\
\hline Jordon & -1.143 & {$[0]$} & $-2.397 \quad[4]$ & 0.241 & $(4)$ & $0.148^{\mathrm{b}}$ & (4) & -1.138 & {$[0]$} & -1.529 & [0] \\
\hline Lao PDR & -1.688 & {$[0]$} & $-1.547 \quad[0]$ & 0.143 & $(4)$ & $0.140^{\mathrm{c}}$ & (4) & -1.586 & {$[0]$} & -1.604 & [0] \\
\hline Malaysia & -2.384 & {$[1]$} & $-2.935 \quad[1]$ & 0.268 & $(4)$ & 0.060 & (3) & $-2.412^{b}$ & {$[1]$} & -2.869 & [1] \\
\hline Maldives & -1.839 & {$[0]$} & $-1.540 \quad[0]$ & $0.438^{c}$ & (2) & $0.172^{b}$ & (4) & -1.585 & {$[0]$} & -1.622 & [0] \\
\hline Nepal & -1.663 & {$[0]$} & $0.265 \quad[2]$ & $0.398^{\mathrm{c}}$ & $(2)$ & $0.190^{\mathrm{b}}$ & (4) & -1.065 & {$[0]$} & -0.451 & [0] \\
\hline Oman & -1.406 & {$[0]$} & $-1.855 \quad[0]$ & $0.388^{\mathrm{c}}$ & $(2)$ & $0.162^{b}$ & (4) & -1.287 & {$[0]$} & -1.641 & [0] \\
\hline Pakistan & -1.001 & {$[0]$} & $-1.864 \quad[0]$ & $0.358^{c}$ & (3) & $0.174^{\mathrm{b}}$ & (4) & -1.056 & {$[0]$} & -1.638 & {$[0]$} \\
\hline Philippines & -0.652 & {$[0]$} & $-1.787 \quad[0]$ & 0.308 & (4) & 0.092 & (3) & -0.814 & {$[0]$} & -1.641 & [0] \\
\hline Sri Lanka & -0.720 & {$[0]$} & $-2.193[0]$ & $0.388^{c}$ & (4) & $0.156^{\mathrm{b}}$ & (4) & -0.820 & {$[0]$} & -1.733 & [0] \\
\hline Syrian & -0.746 & {$[0]$} & $-1.536 \quad[0]$ & $0.362^{\mathrm{c}}$ & $(2)$ & $0.182^{b}$ & (4) & -0.764 & {$[0]$} & -1.200 & [0] \\
\hline Thailand & -1.602 & {$[1]$} & $-1.592 \quad[1]$ & 0.139 & (4) & $0.138^{\mathrm{c}}$ & (4) & -1.605 & {$[1]$} & -1.682 & [1] \\
\hline Turkey & -1.870 & {$[0]$} & $-1.950 \quad[0]$ & 0.346 & (4) & 0.080 & (3) & $-1.664^{\mathrm{c}}$ & {$[0]$} & -2.030 & {$[0]$} \\
\hline Vietnam & -1.936 & {$[0]$} & $-1.992 \quad[2]$ & 0.141 & (4) & $0.125^{\mathrm{c}}$ & (4) & $-1.855^{\mathrm{c}}$ & {$[0]$} & -1.959 & [0] \\
\hline
\end{tabular}

Notes: $\left({ }^{a}\right),\left({ }^{b}\right)$ and $\left({ }^{c}\right)$ denote significant at 1,5 and $10 \%$ significance level, respectively. $\theta$ and $\tau$ denoted as no trend and with trend, respectively. The value in [ ] refer to lag length selected by SIC, while value in ( ) for the KPSS test denoted as bandwidth selected by Newey-West Bandwidth HACC estimator with Bartlett weights. Both the ADF and DFGLS tests examine the null hypothesis of a unit root against the stationarity alternative. KPSS tests the stationarity null hypothesis against the alternative hypothesis of a unit root.

and trend $[N=-1.586 ; p$-value $=0.056]$ reject the null hypothesis of nonstationary. As noted in earlier studies, these results need to be cautiously interpreted because the joint null of nonstationarity may be rejected when a small fraction of the series in the panel is stationary (see also Table 1). Additionally, it should be noted that the presence of cross-sectional dependence could lead to over rejection of the null hypothesis joint nonstationarity (Breuer et al. 2002; Holmes 2006). These rejections are in fact opposite to the results based on the univariate ADF tests, where it is shown that few but not all the series are stationary.

Breuer et al. (2001, BMW) argued that panel unit root tests are flawed because "they are incapable of determining the mix of $I(0)$ and $I(1)$ series in a panel setting" (BMW: 482 ) and the conclusion of the test applies to all members of the panel even though 
the panel may include a mixture of $I(0)$ and $I(1)$ variables. From this perspective, the panel unit root tests are less informative unless there are strong reasons to believe that all the members of the panel have the same integration property. This is not true in our case as we have shown earlier that our panel is a mixture of $I(1)$ and $I(0)$ variables. Additionally, most of the first generation panel unit root tests are designed for crosssectional independent panels, which are unlikely to be met in most panels, especially in a globalized economy where shocks are known to over-pass country borders. We take up this issue in the next section.

\subsection{SURADF evidence}

As demonstrated earlier, we found that the individual univariate unit root tests are indeed the realization of a mixture of $I(0)$ and $I(1)$ processes. Furthermore, the panel results demonstrated that the probability of stationarity for the panel increased as the number of $I(0)$ composition increased within the panel. One useful way to resolve this ambiguity is to apply a more powerful test. To this end, we turned to the SURADF test, a test shown by Breuer et al. (2002) and BMW (2001) to perform reasonably well with a mixed order of integration in the panel and then test for individual unit roots within the panel members.

Table 2 displays the results for SURADF estimation for both constant and constant and trend models. Interestingly, the results indicate that the test statistics for nine of the countries reject the unit root null, testifying stationary characteristic in some, but not for all the countries under review. As can be seen from Table 2, the list of countries includes Bangladesh, Bhutan, Indonesia, Jordan, Malaysia, Maldives, Nepal, Syrian and Turkey. The external debts in these nine Asian countries were indeed sustainable. For the remaining countries, the external debts were confirmed to be on an unsustainable path. Therefore, there is mixed evidence to support the sustainability of the fiscal positions in the 19 developing countries. However, it is worth mentioning here that the SURADF test is designed for a more restrictive scenario despite its superiority over the first generation panel unit root tests. Our results also reveal that the SURADF test has superior performance over the univariate ADF test in identifying stationary process. By comparison, a more nonstationary null is rejected in the panel over the single equation ADF based on the level of significance as indicated in Table 2. The conclusion regarding stationarity is ambiguous, depending on which countries are taken as panel members. Certainly the issue structural breaks were not being addressed by the econometric model so far.

\subsection{Panel data stationarity test with structural breaks}

Most of the studies recognize the potential importance of cross-section error dependence in panel regressions, but few have provided evidence of its statistical significance. The Pesaran's (2004) cross-section dependence test is shown to be quite robust in the presence of unit roots and structural breaks. As shown in Table 3, we observed a high cross-sectional dependency for the countries in the Asian region. Consequently, there is a need to accommodate cross-section dependence in the panel unit root test. To deal 
Table 2. SURADF estimation and the critical values

\begin{tabular}{|c|c|c|c|c|c|c|c|c|}
\hline \multirow{2}{*}{$\begin{array}{l}\text { Country } \\
\text { panel label }\end{array}$} & \multirow{2}{*}{$\begin{array}{c}\text { Test Statistics } \\
\text { SURADF } \\
\text { (Constant) }\end{array}$} & \multicolumn{3}{|c|}{ Critical Values } & \multirow{2}{*}{$\begin{array}{c}\text { Test } \\
\text { Statistics } \\
\text { SURADF } \\
\text { (Constant } \\
\text { and trend) }\end{array}$} & \multicolumn{3}{|c|}{ Critical Values } \\
\hline & & 0.01 & 05 & 10 & & 0.01 & 0.05 & 0 \\
\hline Bangladesh & $-4.58 /(1)$ & .526 & 4.804 & -3.720 & $-4.742(1)^{*}$ & -5.550 & -4.844 & -0.111 \\
\hline Bhutan & $-4.234(2)^{*}$ & -5.768 & -5.021 & -3.907 & $-3.950(1)^{*}$ & -5.760 & -4.993 & -3.878 \\
\hline China & $-2.766(1)$ & -5.657 & -4.913 & -3.796 & $-3.152(1)$ & -5.662 & -4.892 & -3.818 \\
\hline India & $-2.120(2)$ & -5.300 & -3.557 & -2.365 & $-2.280(2)$ & -5.558 & -3.536 & -2.340 \\
\hline Indon & $-4.437(1)^{*}$ & -5.205 & -4.549 & -3.442 & $-4.719(1)^{* *}$ & -5.145 & -4.448 & -3.428 \\
\hline Iran & -3.1 & -5.146 & -4.448 & -3.202 & $-3.235(1)$ & -5.117 & -4.413 & -3.257 \\
\hline Jordan & $-4.397(1)^{*}$ & -5.618 & -4.795 & -3.493 & $-4.274(1)^{*}$ & -5.574 & -4.748 & -3.439 \\
\hline Lao & -2.5 & -5.260 & -4.591 & -3.538 & -2.402 & -5.234 & -4.537 & -3.512 \\
\hline Mala & -3.757 & -5.378 & -4.648 & -3.582 & $-3.584(1)^{*}$ & -5.273 & -4.565 & -3.562 \\
\hline Maldives & $-3.607(1)^{*}$ & -5.225 & -4.571 & -3.556 & $-3.618(2)^{*}$ & -5.228 & -4.576 & -3.525 \\
\hline Nepal & $-5.128(2)^{* *}$ & -5.312 & -4.623 & -3.557 & $-5.197(2)^{* *}$ & -5.360 & -4.642 & -3.552 \\
\hline Oman & -3.065 & -5.257 & -4.594 & -3.535 & $-3.116(1)$ & -5.197 & -4.545 & -3.536 \\
\hline Pakistan & $-1.179(2)$ & -5.287 & -4.582 & -3.536 & $-2.046(2)$ & -5.284 & -4.604 & -3.587 \\
\hline Philippines & $-1.451(2)$ & -4.964 & -4.249 & -3.087 & $-2.117(2)$ & -4.963 & -4.276 & -3.056 \\
\hline Sri Lanka & $-0.724(1)$ & -5.139 & -4.474 & -3.430 & $-1.818(1)$ & -5.168 & -4.464 & -3.445 \\
\hline Syrian & $-4.227(1)^{*}$ & -5.225 & -4.550 & -3.538 & $-5.000(1)^{*}$ & -6.087 & -5.294 & -4.095 \\
\hline Thailand & $-2.184(2)$ & -5.986 & -5.219 & -4.086 & $-2.124(2)$ & -5.256 & -4.570 & -3.550 \\
\hline Turkey & $-3.992(2)^{*}$ & -5.219 & -4.536 & -3.504 & $-3.944(2)^{*}$ & -5.285 & -4.558 & -3.481 \\
\hline Vietnam & $-2.093(3)$ & -6.887 & -6.001 & -4.611 & $-1.994(3)$ & -6.938 & -6.097 & -4.609 \\
\hline
\end{tabular}

Notes: The column of SURADF refers to the estimated ADF statistics obtained through the SUR estimation of the ADF regression. The SURADF examine the null hypothesis of a unit root against the stationarity alternative. The three right hand columns report the estimated critical values tailored by the simulation experiments based on 30 observations for each series and 10,000 replications, following the work by Breuer et al. (2002). The error series were generated in such a manner to be normally distributed with the variance-covariance matrix given from the SUR estimation of the 19 countries panel structures. Each of the simulated balancing items was then generated from the error series using the SUR estimated coefficients on the lagged differences. $(* *)$ and $\left({ }^{*}\right)$ denote statistical significance at the 0.05 and 0.10 level. Figures in parentheses indicate the lag length.

Table 3. Pesaran cross dependency (PCD) tests for 19 countries

\begin{tabular}{lccc}
\hline & $p=0$ & $p=1$ & $p=2$ \\
\hline Reject $\mathrm{H}_{0}$ when the test statistic $P C D=\sqrt{2 T / N(N-1)} \sum_{i=1}^{N-1} \sum_{j=i+1}^{N} \hat{\rho}_{i j}>N(0,1)=1.96$. \\
\hline No constant nor trend & $10.98^{\mathrm{a}}$ & $10.46^{\mathrm{a}}$ & $10.06^{\mathrm{a}}$ \\
\hline Constant & $10.57^{\mathrm{a}}$ & $10.38^{\mathrm{a}}$ & $10.67^{\mathrm{a}}$ \\
\hline Constant and trend & $8.97^{\mathrm{a}}$ & $8.76^{\mathrm{a}}$ & $8.44^{\mathrm{a}}$ \\
\hline
\end{tabular}

Notes: $\left({ }^{a}\right)$ denotes significant at 5\% significance level. The Pesaran's (2004) PCD test is based on the residual cross correlation of the $\mathrm{ADF}(p)$ regressions, where $p$ denotes the lag. The test follows a standard normal distribution under the null hypothesis of cross-sectional independence. 
with the possibility of both breaks and cross-section dependence in the panel analysis, we conducted the panel stationarity test developed by the CDL (2005).

In the present study, the pure structural change model, which allows the entire coefficient to change, is considered. Since the short span of the annual data employed in this study, we then allow for a maximum of two breaks. Based on this algorithm, we found most of the tests $\left(\sup F_{T}(0 \mid 1), \sup F_{T}(0 \mid 2), U D \max , W D \max\right.$ and $\left.\sup F_{T}(2 \mid 1)\right)$ are significant at the $10 \%$ significance level or even better for these 19 countries. The results are reported in Table 4, panel A.

There is disparity in the location of break dates from country to country, which is partly due to country characteristics and the policy initiatives taken during the sample period. It also suggests that the effects of these reforms are not immediate. The break points that have been identified in the table correspond with important events. The first break date is mostly found around the 1987-1988 period. Reinhart and Rogoff (2009: 23) reported that in countries such as Iran and Jordan, the default or restructuring dates were within the threshold of this date. Further, within the 1986-1988 periods, Bangladesh, Lao PDR, Malaysia and Nepal were experiencing banking crises (Reinhart, Rogoff 2009, Appendix 4). Furthermore, this period is associated with the mid-1980s economic recession and its aftermath. We note here that around $50 \%$ of the countries had been affected by the commodity crisis, putting pressures on their external debts and sustainability for some countries. According to our results, the impact of the economic reforms on debt management seems to take place two to three years after the economic recession.

The second break can be mostly located from the late -1990 s to early 2000 s. For Turkey, the break date location in 1998 coincided with the collapse of the economy (Önel, Utkulu 2006). For Thailand, the second break was in conjunction with the Asian financial crisis and its aftermath recoveries. In some countries, break dates are detected several years before or after the 1997 crisis. The period before 1997 corresponds with the imbalances in the current account, while large fiscal deficits increased substantially after the 1997 crisis especially for the Asian countries (Lau, Baharumshah 2009). In the 1997 crisis episode, the governments of these countries pursue in expansionary fiscal policy aimed at stimulating the economy, which put pressure on the government fiscal position. Additionally, policymakers in many of these countries launched several debt restructuring and macroeconomic adjustment programs to reduce the demand for external financing. These include the development of domestic bond markets in some of the countries (e.g., India, Indonesia, Malaysia and Turkey). Other factors that have contributed to the changing debt pattern include a corporate preference to borrow domestically rather than externally due to risk adverse perceptions and a return to the 1997 pre-crisis sustained economic growth path.

In order to test for sensitivity of the results, we truncate the sample countries into three groups: (a) a full panel consisting of a sample of 19 countries $(N=19)$, (b) a sub-panel excluding 10 countries (including China and India) of the original countries in the panel $(N=9)$ that are found to be nonstationary in the SURADF estimation, and (c) a sub-panel that consists of 10 countries that have been categorized as nonstationary by 


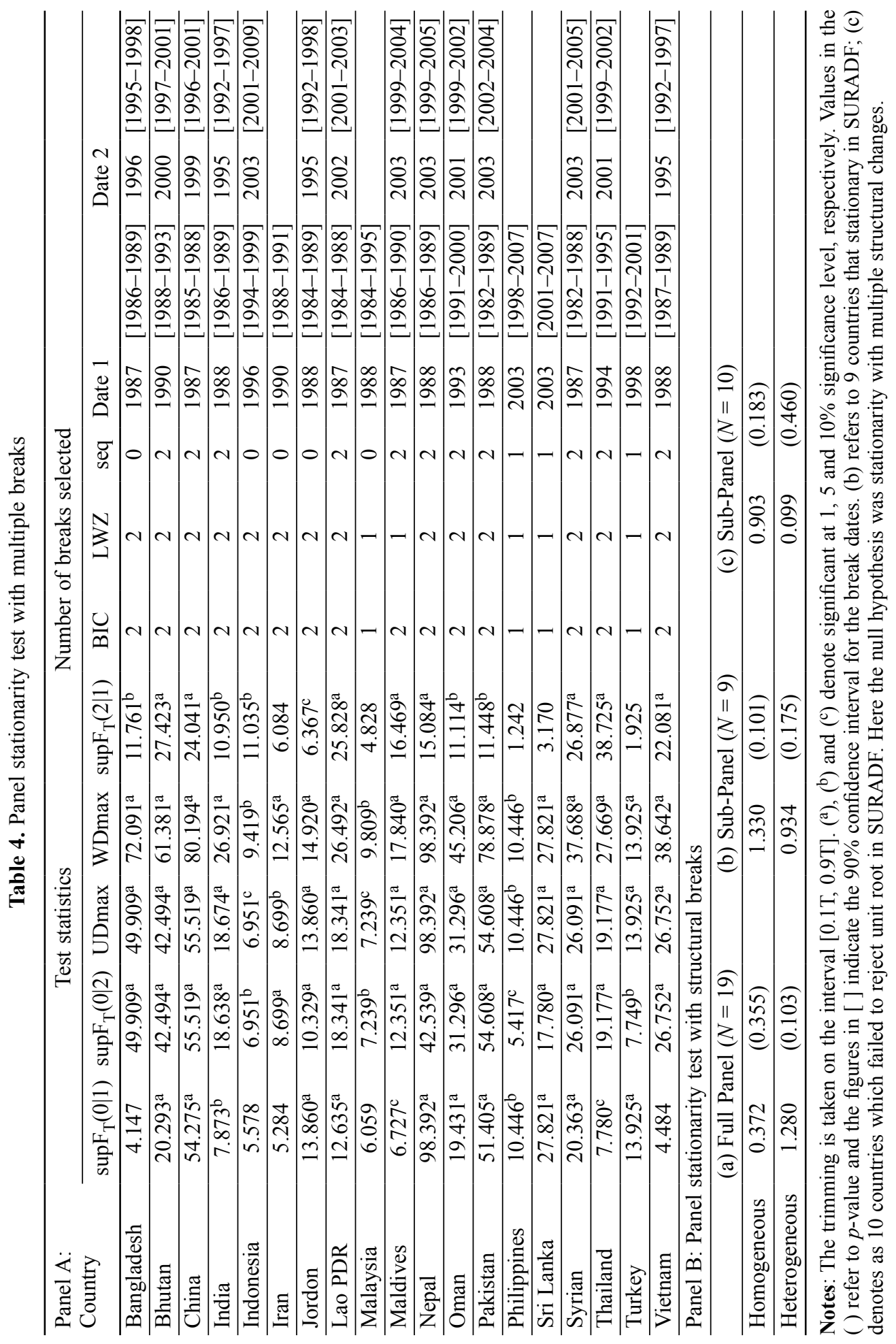


SURADF test. The panel stationarity tests that accommodate multiple breaks for the three different panel members are reported as per Table 4, panel B. As can be seen from the last two rows in Table 4, the evidence seems strongly in favor of mean-reverting, and the results are independent of the members selected in the panel. This finding tends to highlight the importance of structural breaks in testing the sustainability (stationarity) of external debts in the set of Asian countries under review ${ }^{7}$. We conclude that sustainability of external debts is a characteristic of the Asian countries, at least for the sample period that ended in $2010^{8}$. Our results from the test appear to be insensitive to the countries included in the panels that account for cross dependency and multiple breaks. In sum, we find weak sustainability using the panel SURADF, which tests the null of non-stationarity. The outcome from the CDL (2005) that tests the null of stationarity appears to support sustainability in the spirit of Hamilton and Flavin (1986). We also notice that the dating of the break dates varies across the sample countries. This may be due to different timing and intensity of the debt management program in the countries under review.

\section{Conclusions}

This article presents an alternative test procedure that exploits the power of panel data methods without imposing uniformity across the panel under either the null or the alternative hypotheses to test for the mean reversion behavior of external debt in 19 Asian countries. The empirical results from this study lead to several important conclusions. First, we found contradicting results between the conventional univariate data based tests and several of the first generation panel unit root testing procedures typically used to test the sustainability issue. Although the former tests show that most of the countries in Asian are not level stationary, the latter provides significant results that there is at least one stationary country in the panel. It is well known that this apparent contradicting finding could be attributed to the low statistical power of the single-equation unit root procedures.

Second, we applied the SURADF estimation procedures in order to uncover which members of the panel possess mean-reverting behavior. From the SURADF estimation, we conclude that only nine of the countries under observations have mean-reverting external debt (the lists include Bangladesh, Bhutan, Indonesia, Jordan, Malaysia, Maldives, Nepal, Syrian and Turkey). For the remaining countries, there is evidence that their external debt is insolvent.

Finally, we allowed for multiple breaks in the individual series of the panel and performed the test proposed by CDL (2005). Two additional points are worth mentioning

\footnotetext{
${ }^{7}$ Like Holmes (2006), we also find the evidence from SURADF test is mixed. Holmes et al. (2010) also presented two sets of results that differ only in the selection of panel members. The evidence in panel with the EU countries is found to be stationary (sustainable), but the opposite is true in the case of non-EU countries. They went on to conclude that it is very likely that the long-run budget constraint is upheld for the EU countries during the period under investigation.

${ }^{8}$ Consistently, we found a similar conclusion in the earlier version of the paper with data up to 2006 (before the GFC).
} 
here with regard to the application of panel stationarity test that accommodate cross dependence and structural breaks to the same data set. First, the break tests reveal that the timing of the breaks occurred on different dates in different countries. In the majority of countries (14 out of 19), we found that the series are best characterized by two breaks with the majority of the second break located between 1999-2003. Second, once the breaks are taken into account in the estimations, the external debt is found to be mean-reverting. The evidence is present for both full and sub-samples of countries. Therefore, all countries under review are said to be solvent in terms of their external debt, at least for the period under observation.

From a policy perspective, it is important for the government to maintain a sustainable path of economic growth in the near future ${ }^{9}$. Empirical evidence has shown that both domestic inefficiencies and imported panic are important for explaining the sharp fall in output in recent years. The debt crises of the 1980s are a case in point. One straightforward policy adjustment would be to determine the optimal debt levels that could be targeted for each country. Once it is known, policy makers could act fast to reduce the debts when it is near (or above) the estimated threshold. Among the collective action would be the debt optimality strategies (e.g., debt stabilizing). The pursuit of debt-targeting policy/rule is likely to result in sound public finances. With the sluggish domestic demand and volatile outlook across the developed nations (especially Euro Area), it is important for solvency in external debt positions for Asian developing countries and it should be implemented by proactive government measures to accelerate economic activities.

\section{Acknowledgements}

This paper has benefited from the constructive comments of two anonymous referees and the managing editor of this journal. This study has also benefited from the conference participants at the Fifth International Conference on Interdisciplinary Social Sciences held in University of Cambridge, UK. The authors gratefully acknowledges financial support from the Ministry of Higher Education Malaysia [FRGS grants No: 05/(35)/843/2012(83)]. The usual disclaimer regarding errors and omissions applies.

\section{References}

Ahmed, S.; Rogers, J. H. 1995. Government budget deficits and trade deficits: are present value constraints satisfied in long-term data?, Journal of Monetary Economics 36(2): 351-374.

http://dx.doi.org/10.1016/0304-3932(95)01215-X

Bajo-Rubio, O.; Díaz-Roldán, C.; Esteve, V. 2009. Deficit sustainability and inflation in EMU: an analysis from the fiscal theory of the price level, European Journal of Political Economy 25(4): 525-539. http://dx.doi.org/10.1016/j.ejpoleco.2009.04.001

\footnotetext{
${ }^{9}$ Hauptmeier et al. (2011) noted that rule-based expenditure policies could have led to much safer fiscal positions much more in line with the EU's Stability and Growth Pact. The lesson drawn from the Euro Area would constitute essential planning for the countries here in managing future expenditure and fiscal "in(sanity)" rule.
} 
Baldacci, E.; Gupta, S.; Mulas-Granados, C. 2010. Restoring debt sustainability after crises: implications for the fiscal mix, International Monetary Fund (IMF) Working Paper No. 10/232, $1-35$.

Berg, A.; Sachs, J. 1988. The debt crisis: structural explanations of country performance, Journal of Development Economics 29(3): 271-306.

Bohn, H. 2007. Are stationarity and cointegration restrictions really necessary for the intertemporal budget constraint?, Journal of Monetary Economics 54(7): 1837-1847.

http://dx.doi.org/10.1016/j.jmoneco.2006.12.012

Breuer, J. B.; McNown, R.; Wallace, M. S. 2001. Misleading inferences from panel unit-root tests with an illustration from purchasing power parity, Review of International Economics 9(3): 482-493. http://dx.doi.org/10.1111/1467-9396.00294

Breuer, J. B.; McNown, R.; Wallace, M. S. 2002. Series-specific unit root tests with panel data, Oxford Bulletin of Economics and Statistics 64(5): 527-546.

http://dx.doi.org/10.1111/1468-0084.00276

Carrion-i-Silvestre, J. L.; del Barrio Castro, T.; López-Bazo, E. 2005. Breaking the panels: an application to the GDP per capita, Econometrics Journal 8(2): 159-175.

http://dx.doi.org/10.1111/j.1368-423X.2005.00158.x

Cassimon, D.; Moreno-Dodson, B.; Wodon, Q. 2008. Debt sustainability for low-income countries: a review of standard and alternative concepts, in B. Moreno-Dodson, Q. Wodon (Eds.). Public finance for poverty reduction: concepts and case studies from Africa and Latin America. World Bank Directions in Development, 21-56.

Chaudhary, M. A.; Anwar, S. 2001. Debt Laffer curve for South Asia for countries, The Pakistan Development Review 40(4): 705-720.

Christopoulos, D.; León-Ledesma, M. A. 2010. Current account sustainability in the US: what did we really know about it?, Journal of International Money and Finance 29(3): 442-459.

http://dx.doi.org/10.1016/j.jimonfin.2009.06.014

Elliott, G.; Rothenberg, T. J.; Stock, J. H. 1996. Efficient tests for an autoregressive unit root, Econometrica 64(4): 813-836.

Fincke, B.; Greiner, A. 2011. Do large industrialized economies pursue sustainable debt policies? A comparative study for Japan, Germany and the United States, Japan and the World Economy 23(3): 202-213. http://dx.doi.org/10.1016/j.japwor.2011.03.002

Hadri, K. 2000. Testing for stationarity in heterogenous panel data, The Econometrics Journal 3(2): 148-161. http://dx.doi.org/10.1111/1368-423X.00043

Hamilton, J. D.; Flavin, M. A. 1986. On the limitations of government borrowing: a framework for empirical testing, American Economic Review 76(4): 808-819.

Hauptmeier, S.; Sanchez-Fuentes, A. J.; Schuknecht, L. 2011. Towards expenditure rules and fiscal sanity in the euro area, Journal of Policy Modeling 33(4): 597-617.

http://dx.doi.org/10.1016/j.jpolmod.2011.03.006

Hlouskova, J.; Wagner, M. 2006. The performance of panel unit root and stationarity tests: results from a large scale simulation study, Econometric Reviews 25(1): 85-116.

http://dx.doi.org/10.1080/07474930500545504

Holmes, M. J. 2006. How sustainable are the OECD current account balances in the long run?, Manchester School 74(5): 626-643. http://dx.doi.org/10.1111/j.1467-9957.2006.00514.x

Holmes, M. J.; Otero, J.; Panagiotidis, T. 2010. On the stationarity of current account deficits in the European Union, Review of International Economics 18(4): 730-740.

http://dx.doi.org/10.1111/j.1467-9396.2010.00896.x 
Im, K. S.; Pesaran, M. H.; Shin, Y. 2003. Testing for unit roots in heterogeneous panels, Journal of Econometrics 115(1): 53-74. http://dx.doi.org/10.1016/S0304-4076(03)00092-7

Johansson, P. 2010. Debt relief, investment and growth, World Development 38(9): 1204-1216. http://dx.doi.org/10.1016/j.worlddev.2009.11.021

Kim, B.-H.; Min, H.-G.; Hwang, Y.-S.; McDonald, J. A. 2009. Are Asian countries' current account sustainable? Deficits, even when associated with high investment, are not costless, Journal of Policy Modeling 31(2): 163-179. http://dx.doi.org/10.1016/j.jpolmod.2008.08.001

Kraay, A.; Nehru, V. 2006. When is external debt sustainable?, The World Bank Economic Review 20(3): 341-365.

Kwiatkowski, D.; Phillips, P. C. B.; Schmidt, P.; Shin, Y. 1992. Testing the null hypothesis of stationarity against the alternative of a unit root: how sure are we that economic time series have a unit root?, Journal of Econometrics 54(1-3): 159-178.

http://dx.doi.org/10.1016/0304-4076(92)90104-Y

Lau, E.; Baharumshah, A. Z. 2009. Assessing the mean reversion behaviour of fiscal policy: the perspective of Asian countries, Applied Economics 41(15): 1939-1949.

http://dx.doi.org/10.1080/00036840601131755

Levin, A.; Lin, C. F.; Chu, C.-S. 2002. Unit root tests in panel data: asymptotic and finite-sample properties, Journal of Econometrics 108(1): 1-24.

http://dx.doi.org/10.1016/S0304-4076(01)00098-7

Makrydakis, S.; Tzavalis, E.; Balfoussias, A. 1999. Policy regime changes and the long-run sustainability of fiscal policy: an application to Greece, Economic Modelling 16(1): 71-86.

http://dx.doi.org/10.1016/S0264-9993(98)00026-1

McFadden, D.; Richard, E.; Gershon, F.; Vassilis, H.; O’Connell, S. 1985. Is there life after debt? An econometric analysis of the 27 creditworthiness of developing countries, in G. Smith, J. Cuddington (Eds.). International debt and the developing countries. World Bank, Washington, DC, 179-209.

Muhanji, S.; Ojah, K. 2011. External shocks and persistence of external debt in open vulnerable economies: the case of Africa, Economic Modelling 28(4):1615-1628.

http://dx.doi.org/10.1016/j.econmod.2011.02.020

Önel, G.; Utkulu, U. 2006. Modeling the long-run sustainability of Turkish external debt with structural changes, Economic Modelling 23(4): 669-682.

http://dx.doi.org/10.1016/j.econmod.2006.03.006

Pesaran, M. H. 2004. General diagnostic tests for cross-section dependence in panels, Cambridge Working Papers in Economics (CWPE) No. 0435. University of Cambridge.

Quintos, C. E. 1995. Sustainability of the deficit process with structural shifts, Journal of Business and Economic Statistics 13(4): 409-417.

Reinhart, C. M.; Rogoff, K. 2009. This time is different: eight centuries of financial folly. New Jersey: Princeton University Press.

Said, S. E.; Dickey, D. A. 1984. Testing for unit roots in autoregressive-moving average models of unknown order, Biometrika 71(3): 599-607.

Takeuchi, F. 2010. US external debt sustainability revisited: bayesian analysis of extended Markov switching unit root test, Japan and the World Economy 22(2): 98-106.

http://dx.doi.org/10.1016/j.japwor.2009.12.001

Thugge, K.; Boote, A. R. 1997. Debt relief for low income countries and the HIPC initiative, International Monetary Fund (IMF) Working Paper No. WP/97/24, 1-29.

Trehan, B.; Walsh, C. E. 1988. Common trends, the government budget constraint, and revenue smoothing, Journal of Economic Dynamics and Control 12(2-3): 425-444.

http://dx.doi.org/10.1016/0165-1889(88)90048-6 
Trehan, B.; Walsh, C. 1991. Testing intertemporal budget constraints: theory and applications to U.S. Federal budget and current account deficits, Journal of Money, Credit and Banking 23(2): 206-223.

Uctum, M.; Wickens, M. 2000. Debt and deficit ceilings and sustainability of fiscal policies: an intertemporal analysis, Oxford Bulletin of Economics and Statistics 62(2): 197-222.

http://dx.doi.org/10.1111/1468-0084.00168

Evan LAU is currently serving as a senior lecturer at the Faculty of Economics and Business, Universiti Malaysia Sarawak (UNIMAS) and Managing Editor of International Journal of Business and Society (IJBS). To date, he has published more than 60 articles.

\begin{abstract}
Ahmad Zubaidi BAHARUMSHAH is a Professor at the Department of Economics, Faculty of Economics and Management, Universiti Putra Malaysia. His area of interest is in International Finance and Macroeconomics and to date has published more than 80 research articles.
\end{abstract}

Siew-Voon SOON is a graduate student at the Department of Economics, Faculty of Economics and Management, Universiti Putra Malaysia. Her area of interest is in Macroeconomics. 